\title{
Wanting, Having, and Needing: Integrating Motive Disposition Theory and Self-Determination Theory
}

\author{
Kennon M. Sheldon \\ University of Missouri
}

\author{
Julia Schüler \\ University of Zurich
}

\begin{abstract}
Four studies explored the motivational and experiential dynamics of psychological needs, applying both self-determination theory and motive disposition theory. In all 4 studies, motive dispositions toward achievement and affiliation ("wanting" particular experiences) predicted corresponding feelings of competence and relatedness ("having" those experiences). Competence and relatedness in turn predicted well-being, again indicating that these 2 experiences may really be "needed." Illuminating how wanting gets to having, in Studies 2 and 3, participants reported greater self-concordance for motive-congruent goals, which, in longitudinal Study 3, predicted greater attainment of those goals and thus enhanced well-being. Study 4 replicated selected earlier results using an implicit as well as an explicit motive disposition measure. Supporting the presumed universality of competence and relatedness needs, in no studies did motive dispositions moderate the effects of corresponding need-satisfaction on well-being. Discussion focuses on a "sequential process" model of psychological needs that views needs as both motives that instigate and outcomes that reward behavior.
\end{abstract}

Keywords: self-determination theory, motive disposition theory, psychological needs, goals, selfconcordance

It is clear that understanding the mind's neural and socialcognitive machinery may do us limited good, if we do not understand what people want and what they are striving to do as they employ this machinery (Emmons, 1989; Carver \& Scheier, 1998). Psychological need constructs have long played a central role in addressing these essential questions, because they concern the basic motivations and desires that move people through life. Psychological needs presumably supply the "why" of much behavior, and thus, need theories provide a theoretical lens from which to consider both the functions of lower level processes and how successfully those processes fulfill their functions.

However, psychological need research has been plagued by numerous conundrums and paradoxes, brought about by the widely varying definitions of needs that exist and widely varying understandings of how they work. Should basic psychological needs be conceptualized as implicit or nonconscious motives that orient people automatically toward varying incentives in the world (Schultheiss, 2008), or should they be conceptualized as explicit requirements for particular types of conscious experience that bring satisfaction and growth (Deci \& Ryan, 1985)? Do needs vary across different people, life stages, contexts, and cultures, or are they universal and invariant across people, stages, contexts, and cultures (Maslow, 1971)? Are needs acquired through development and learning, or are they inherent within the human genome
(White, 1959)? If needs are inherent within the genome, are they species-typical characteristics shared by everyone, or are there instead heritable variations in the relevant genes (Tooby \& Cosmides, 1990)? As these questions show, there are important disagreements on whether needs are behavioral motives pushing out versus experiential requirements that need to come in, whether needs are implicit and nonconscious versus explicit and conscious, whether needs vary across people versus are universal across people, and whether needs are innate and inherited versus acquired and learned.

The current research sought to shed new light on several of these issues by simultaneously testing and integrating propositions from two major need theories: motive disposition theory (MDT; McClelland, 1985) and self-determination theory (SDT; Deci \& Ryan, 1985; Schüler, Sheldon, \& Fröhlich, 2010; Sheldon \& Cooper, 2008). In particular, we hope to show that individual differences in the motive for particular experiences (i.e., wanting) actually pay off (i.e., having), largely by producing more self-concordant motivation for and, thus, greater attainment of motive-relevant goals (Sheldon \& Elliot, 1999). However, we also show that wanting an experience more does not necessarily mean that getting it more provides more benefits; all people benefit equally from basic need-satisfaction. The presented research is integrative not only for linking the process perspectives and predictions of MDT and SDT within a single model but also because it links the needs for achievement and affiliation with the thematically similar needs for competence and relatedness, a link that has not been made before. In addition, the research is integrative, because it uses the concept of personal goals (i.e., specific action units endowed with motivational energy) to show how motive dispositions actually produce need-satisfaction. Finally, this research validates the concept of "self-concordance" (Sheldon, 2004; Sheldon \& Elliot, 1999) in a new way by showing that objectively motive-congruent goals are 
rated as more self-concordant. Below we consider the two theories on which this reasoning is based.

\section{Motive Disposition Theory}

Motive disposition theory (MDT) originated in the pioneering clinical and theoretical writings of Henry Murray (1938), ideas that were later picked up and extended for research purposes by McClelland, Atkinson, and others. Motive dispositions were defined as learned or acquired orientations toward certain natural incentives in the environment (Atkinson, 1982). For example, the feeling of momentary success is a natural incentive that, if experienced frequently, may result in a strong need for achievement within an individual. Achievement learning begins early, even during toilet training (McClelland, Koestner, \& Weinberger, 1989), and typically involves parents imposing high standards and valuing achievement-related pursuits by the child (McClelland \& Pilon, 1983). Similarly, the feeling of interpersonal closeness is a natural incentive that, if experienced frequently, may result in a strong need for affiliation within an individual. Affiliative learning may begin even sooner than achievement learning, with roots in early attachment security processes. Through social learning and operant conditioning, people may come to rely disproportionately on certain types of naturally positive experiences (Atkinson, 1982; McClelland, 1985), presumably in service of chronic mood-regulation processes (Job \& Brandstätter, 2009; McClelland, 1985). ${ }^{1}$

Motive disposition constructs are still employed today, although they are varyingly measured by purely implicit techniques (i.e., the Thematic Apperception Test [TAT]; Murray, 1943), by purely explicit techniques (i.e., the Personality Research Form or [PRF]; Jackson, 1984), or by mixed techniques (i.e., the Multimotive grid [MMG]; Sokolowski, Schmalt, Langens, \& Puca, 2000). Motive disposition constructs (along with personal goal constructs) can be located at a "middle tier" of personality, between dispositional/ habitual traits at the bottom tier and narrative identities and selfconcepts at the top tier (McAdams, 1996). However, motive dispositions might also be viewed as bottom-tier constructs that are more like traits than like goals (Langens \& Schmalt, 2008; Sheldon, 2004) and which are, to some extent, inherited (Langens \& Schmalt, 2008). Either way, what is important is that motive dispositions apparently function by making people want certain types of natural incentives more than other types. Thus, MDT research typically focuses on individual differences in motives and their effects on various outcomes and behaviors.

\section{Self-Determination Theory}

Why would certain types of experiences function as "natural" incentives for all humans, and what are the most basic natural incentives? To answer these questions, an adaptationist or evolutionary perspective is required (Buss, 1991). SDT (Deci \& Ryan, $1985,2000)$ provides such a perspective. According to SDT, the three basic psychological needs are competence (feeling effective and efficacious in one's behavior), relatedness (feeling close and connected to important others), and autonomy (feeling ownership and internal causation of one's behavior). These needs are hypothesized to be evolved features of basic human nature, which were selected for because feelings of competence, relatedness, and autonomy correspond to the successful negotiation of important and distinct categories of adaptive tasks (Deci \& Ryan, 2000). In other words, it is logical that evolution would reward us with positive feelings when we do something that has adaptive significance, such as producing or succeeding at something, experiencing a close relationship and alliance with another person, or becoming more behaviorally autonomous and self-regulating.

Although Weinberger and McClelland (1990) suggested that excitement-interest-flow is the distinctive positive emotion set that accompanies achievement satisfaction, and joy-happiness-pleasure is the distinctive positive emotion set that accompanies affiliation satisfaction, it seems that either type of emotion set could accompany either type of satisfaction. For example, one might experience joy and pleasure during flow experiences or interest and excitement during conversation. Thus, we suggest that feelings of relatedness and competence satisfaction may offer a more precise way of considering the positive feelings that reinforce attainment of natural affiliation and achievement incentives, respectively. Stated in developmental terms, high need for achievers may be those who got much competence need-satisfaction as children and came to rely on that type of satisfaction. In contrast, high affiliatives may be those who got much early relatedness satisfaction as children and came to rely on this type of satisfaction (although these epigenetic suppositions are consistent with existing research and theory-i.e., Atkinson, 1982; McClelland, 1985-they are not addressed in this research).

SDT's claims concerning psychological needs are typically tested by showing unique relations of each satisfied need with a wide range of positive outcomes (Ryan \& Deci, 2008). The assumption is that satisfied needs support organismic integration processes that bring about psychological thriving and growth, just as plants grow and thrive when their needs for sun, soil, and water are satisfied (Ryan, 1995). And indeed, much research supports the importance of the proposed needs for autonomy, competence, and relatedness, as they have been found to independently predict well-being and thriving within multiple time frames, in multiple cultures, in multiple age groups, and in experimental manipulations of need-satisfaction and deprivation (see Ryan \& Deci, 2008, or Sheldon, 2004, for reviews). In general, the needs are found to play a proximal mediational role, in which they account for the positive effects of more distal circumstances, goals, relationships, or contexts upon well-being and other thriving outcomes (Niemiec, Ryan, \& Deci, 2009; Ryan \& Deci, 2008; Sheldon, 2004; Sheldon

\footnotetext{
${ }^{1}$ Originally, the need for affiliation was considered as a somewhat "needy" social motive, in which the individual craves affirmation and esteem from others (Atkinson, Heynes, \& Veroff, 1958). McAdams (1980) and others focused attention on a more positive social motive, the need for intimacy, as a counterweight to the need for affiliation. It is likely that the needs for affiliation and intimacy are both relevant to SDT's postulated need for relatedness. In this article, the more traditional MDT term "need for affiliation" is employed, because that is the name of the Personality Research Form (PRF) scale that we used to measure interpersonal motivation. Inspection of the PRF items shows that the PRF assesses mostly positive affiliation, as participants rate whether they like to share hobbies with others, whether they enjoy themselves at social functions, whether they are friendly, and so on. This is consistent with the current article's focus on positive motive dispositions that may produce positive states of need-satisfaction. Notably, the need for power, the other major motive disposition, is not considered in this article.
} 
\& Krieger, 2007). Thus, the SDT needs can be modeled both as outcomes of prior contextual or personality processes and as causes of later effects.

An important question that arises is, "Do the three needs always have the same effects on well-being, or can their effects on well-being vary, depending on many possible factors?" Strikingly, almost no studies have shown moderator or interactive effects involving the three basic needs and well-being (but see Richer, Blanchard, \& Vallerand, 2002); that is, the needs do not seem to have different correlations with well-being depending on the person's traits, cultural context, or life stage. This is consistent with SDT's focus on the needs as universal and as operating via very similar processes in everyone. However, it is superficially inconsistent with MDT, because a conventional "motive matching" perspective (Harackiewicz \& Sansone, 1991; Vansteenkiste, Timmerman, Lens, Soenens, \& Van den Broeck, 2008) states that people high in a particular disposition should benefit more when they get experiences that match their disposition. For example, from the MDT matching perspective, a person high in need for achievement should get a bigger "charge" or well-being boost from acing a test than should a person high in need for affiliation, and vice versa for the experience of making a new friend.

Still, from the SDT perspective, even highly affiliation-oriented people still have the same need for competence, even if they do not orient their lives in that direction, just as highly achievementoriented people still have the same need for relatedness, despite orienting their lives more toward competence. Again, people may develop modes of living that provide disproportionate amounts of particular basic needs compared with other needs. Nevertheless, they might all end up with the same overall level of well-being, as long as the same total amount of satisfaction is received.

\section{From Wanting to Having: The Role of Self-Concordant Goals}

In sum, we suggest that motive dispositions impel people to want to have certain needs (and their corresponding natural incentives) more than other people want them. How do motives get from wanting to having? One clue is provided by Sheldon and Cooper's (2008) longitudinal study of agency, communion, goal pursuit, and changes in well-being. These researchers asked 493 communitydwelling participants to set multiple goals for the upcoming year and found that agency motives predicted greater autonomous motivation for assigned work and school goals, whereas communion motives predicted greater autonomous motivation for assigned relationship and parenting goals. In other words, a matching perspective did apply here: Consistent with classic MDT, participants were more energized and internally motivated to pursue assigned goals that were consistent with their dispositions. Autonomous motivation, in turn, predicted successful goal attainment, which predicted enhanced well-being at the end of the year (see also Sheldon \& Elliot, 1999). Thus, the Sheldon and Cooper (2008) research identified a process by which stable motive dispositions might successfully bring about the types of experience that the person prefers: energized goal-pursuit.

Notably, the Sheldon and Cooper (2008) research did not examine basic psychological needs, an important gap because psychological needs are the core explanatory concepts in SDT (and also the focus of this article). Instead, the Sheldon and Cooper
(2008) research focused on a different facet of SDT: the "why" of motivation (Sheldon, Ryan, Deci, \& Kasser, 2004). The "why" concerns the reasons for doing something, the most typical measured reasons being "because it is enjoyable" (intrinsic motivation), "because I believe in it" (identified motivation), "because I should do it" (introjected motivation), and "because I have to do it" (external motivation). These four motivations can be located an internalization continuum, with identified and intrinsic motivations representing internalized and autonomous reasons for acting, and external and introjected motivations representing noninternalized or controlled reasons for acting. ${ }^{2}$

Sheldon and Elliott (1999) and Sheldon and Houser-Marko (2001) also assessed the "why" of participant's self-generated personal goals in proposing the self-concordance model of positive functioning. They showed that self-concordant goal motivation (operationally defined as feeling more autonomous than controlled in one's goal pursuits) ${ }^{3}$ predicts more sustained effort and thus greater longitudinal goal-attainment, which, in turn, predicts increased need-satisfaction and, finally, enhanced well-being. Sheldon and Elliott argued that these effects occur because selfconcordant goals better represent deeper, implicit, or more stable aspects of personality, thereby receiving more sustained funding within the psychic economy. Notably, the self-concordance measure does not require the participant to have knowledge about his or her implicit character; he or she only needs to know whether he or she feels autonomous or controlled in pursuing the goals. However, the supposition that self-concordant goals "correctly represent the person" (Sheldon, 2002) - that is, that they index deep person-goal fit-has not been tested directly. This was an important objective of the current research.

Note that the self-concordance model links personal goal constructs to SDT by linking SDT's "why" of motivation to goals and by showing that goal-attainment predicts boosts in needsatisfaction, which, in turn, mediate the positive goal-attainment effects on well-being. However, the self-concordance model also links personal goal constructs to MDT, because measured selfconcordance is presumed to indicate whether participants have managed to select goals that are consistent with their deeper or implicit personality, in which case the goals will receive more

\footnotetext{
${ }^{2}$ SDT also addresses the content or "what" of motivation, via the concept of extrinsic (money, fame, image) versus intrinsic (intimacy, growth, community) aspirations or values (Kasser, 2002). The predominance of intrinsic over extrinsic valuation (the "what" of motivation) appears to have positive effects on well-being, independently of the effects of the "why" of motivation (Sheldon, Ryan, Deci, \& Kasser, 2004). The current article addresses the content of motivation by examining achievement versus affiliative motivation. However, we make no predictions regarding the relative importance of strong achievement versus affiliative motivation for WB; that is, we do not expect one to be better or more salubrious than the other; achievement and affiliation are both important life tasks for college samples.

${ }^{3}$ Sheldon and Cooper (2008) did not subtract controlled motivation from autonomous motivation, as was done in the Sheldon and Elliott (1999) and Sheldon and Houser-Marko (2001) research, because controlled and autonomous motivations were not negatively correlated in their data, as is typically found. Thus, Sheldon and Cooper (2008) did not use the term "self-concordance." Still, in comparing these two lines of research, autonomy and self-concordance can be interpreted as very analogous constructs.
} 
energy. Similarly, MDT assumes that people are more energized when they find themselves with the opportunity to pursue motivecongruent goals. Thus, the self-concordance model may be an ideal vehicle for linking MDT and SDT.

In the current research, we combined stable motive dispositions, self-concordant goal motivation and later attainment, and varying levels of psychological need-satisfaction and well-being, together within a single dynamic longitudinal model (see Figure 1). We present the model by discussing the specific hypotheses of the research. Studies 1 and 4 test the left half of the model only, ignoring goals (Hypotheses 1-3); Study 2 tests the left half of the model, adding a free-listed goal component to the assessment (Hypotheses 1-4); and Study 3 experimentally tests the full longitudinal model by randomly assigning participants to pursue a particular type of goal (either achievement or relationships) over time (Hypotheses 1-5).

\section{Hypotheses}

Hypothesis 1a: The motive or need for achievement (nAch) will uniquely predict concurrent competence need-satisfaction, and the motive for affiliation (nAff) will uniquely predict concurrent relatedness need-satisfaction. Hypothesis $1 b$ (tested after Hypothesis 2): Correspondent need-satisfaction should mediate any association between the motive and subjective well-being (SWB); in other words, if nAch is associated with SWB, it should be due to the extra competence satisfaction these people receive and similarly for nAff and relatedness need-satisfaction. These two hypotheses, tested in all four studies, are represented on the left side of Figure 1 (Hypothesis $1 \mathrm{~b}$ is represented by the absence of direct paths from motive dispositions to SWB.) Hypothesis 1a relies on the thematic similarities between achievement and affiliation on the one hand and achievement and competence on the other and relies on the assumption that "wanting" or being motivated toward a certain need often pays off, such that individuals tend to be "having" the experiences they want. Notice, however, that the opposite direction of association might be proposed, from a certain perspective: The reason one wants the need might be because one does not have it, a proposition recently supported by the research of Sheldon and Gunz (2009). However, Sheldon and Gunz (2009) measured acute desires for particular need-satisfying experiences, showing they could be predicted by preexisting need-deficiencies; they did not test chronic individual differences in motives for needsatisfying experiences as predictors of current and future need states. In the current research we assumed that people develop general motivational orientations toward the world, or ways of living, which by and large succeed.

Hypothesis 2: Competence, relatedness, and autonomy needsatisfaction should predict concurrent subjective well-being. This hypothesis, represented toward the center of Figure 1 and tested in all four studies, is a precondition for Hypothesis $1 \mathrm{~b}$ and is consistent with past research showing that all three needs are uniquely important for understanding "the thriving, happy person" (Ryan \& Deci, 2008; Sheldon, Elliott, Kim, \& Kasser, 2001). Furthermore, changes in competence, relatedness, and autonomy need-satisfaction should predict longitudinal changes in well-being. This hypothesis, represented on the right side of Figure 1 and tested in Study 3, has also been supported via prior longitudinal research (Niemiec et al., 2009; Sheldon \& Elliott, 1999).

Hypothesis 3: Motive dispositions should not interact with corresponding need-satisfactions to predict concurrent wellbeing. Consistent with SDT's universalist or nonconditional account, and inconsistent with matching perspectives, satisfied needs should have the same effects regardless of who is being satisfied; high achievement strivers should not get more benefit from competence experiences, and high affiliation strivers should not get more benefit from relatedness experiences. Although Hypothesis 3 amounts to hypothesizing the null, the four studies we report here provide ample $N$, statistical power, and opportunity to find interactions between motive dispositions and satisfied needs in predicting wellbeing. We reasoned that if no significant interactions emerge, this would be informative, given that MDT and the matching perspective might expect such interactions, whereas SDT would not.

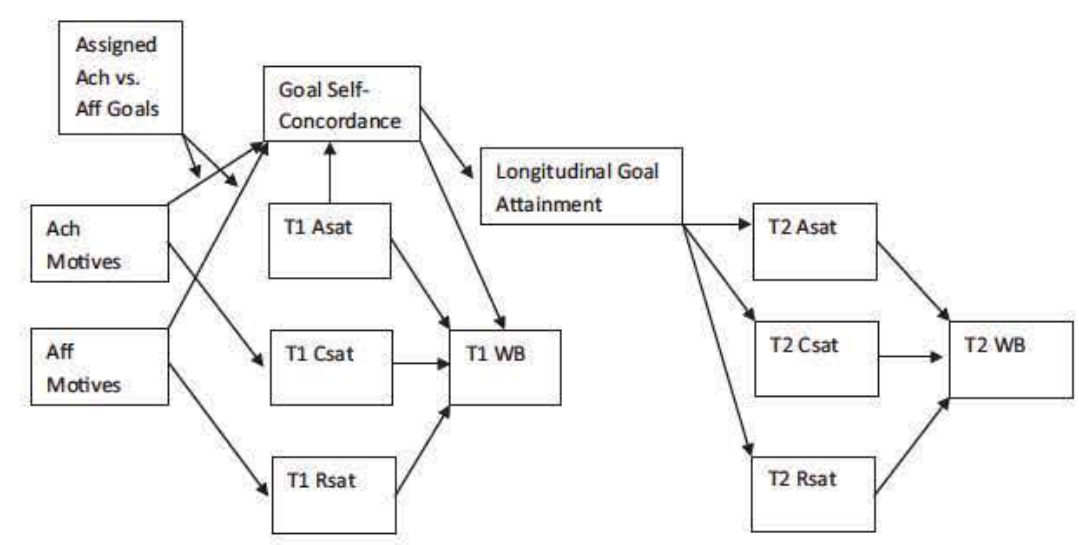

Figure 1. Conceptual path model guiding these studies. Test-retest and error covariance coefficients are omitted. Ach $=$ achievement; Aff $=$ affiliation; Asat $=$ autonomy satisfaction $;$ Csat $=$ competence satisfaction; Rsat $=$ relatedness satisfaction; $W B=$ well-being. 
Hypothesis 4: However, consistent with matching perspectives, motive dispositions should predict greater self-concordance for motive-relevant goals (Sheldon \& Cooper, 2008). This hypothesis, tested in Studies 2 and 3, should manifest as two significant positive interactions: between the need for achievement and the degree to which achievement (rather than affiliation) goals are being rated and between the need for affiliation and the degree to which affiliation (rather than achievement) goals are being rated. These moderator predictions are represented in the top left corner of Figure 1 by the arrows pointing from assigned "achievement versus affiliation" goal to the paths from achievement and affiliation to self-concordance. As discussed above, this hypothesis is based on the self-concordance model assumption that feelings of autonomous, rather than controlled, motivation index person-goal fit, such that a person high in nAch should feel more self-concordant regarding assigned achievement rather than affiliation goals, because achievement goals are matched to his or her achievement disposition, and vice versa for a person high in nAff. The current study provides a new type of test of this assumption.

Hypothesis 5: Hypothesis 5 is actually a set of hypotheses, drawn from the body of published self-concordance research. First, self-concordant goal motivation should predict concurrent subjective well-being (Sheldon \& Kasser, 1995). More important, self-concordant goal motivation should also predict longitudinal goal-attainment, which should, in turn, predict increases in need-satisfaction over the striving period, which should, in, turn predict increases in well-being over that period (Sheldon \& Elliot, 1999). The latter sequence of hypotheses, tested in Study 3 and represented in the middle to right portion of Figure 1, asserts that starting out with more self-concordant goal motivation helps people to do better in and thus benefit more from their goals (Sheldon \& HouserMarko, 2001). This hypothesis can help to explain how participants high in the need for $x$ actually get increases in $x$ need-satisfaction; when they get the opportunity to pursue goals that match $x$ (their enduring interests, values, and dispositions), the resulting self-concordant motivation can produce more effortful and successful goal pursuit.

Notably, autonomy need-satisfaction is not directly relevant to the two motive dispositions under consideration, and, thus, we had no hypotheses concerning relations between nAch, nAff, and felt autonomy. Instead, we included initial autonomy need-satisfaction in the model only as an exogenous variable that should have direct effects on initial well-being consistent with Hypothesis 2 (Reis, Sheldon, Gable, Roscoe, \& Ryan, 2000) and that should also have its own direct effect on self-concordance since self-concordance is construable as a form of autonomy (see Footnote 3).

\section{Study 1}

\section{Method}

Study 1 was a large- $N$ cross-sectional examination of the needs for achievement and affiliation, current satisfaction of the needs for autonomy, competence, and relatedness, and current positive affect in life. Again, Hypotheses 1a, 1b, 2, and 3 were tested.
Participants and procedure. Participants were 939 introductory psychology students at a large public university in the United (420 men and 518 women; one participant did not gender) who took part to help fulfill a course requirement. During the first 2 weeks of the semester, participants completed an online "mass pretest" survey containing the study measures. Although 1,175 participants logged into or began the survey, only participants with complete data on all items relevant to this study were retained.

\section{Measures.}

Motive dispositions. Because of limited survey space, participants completed shortened versions of the achievement and affiliation scales of the Personality Research Form (PRF; Jackson, 1984). Each scale consisted of eight true/false items, four worded positively and four negatively. An example positively worded achievement item is "people should be more involved with their work" and an example affiliation item is "I choose hobbies that I can share with people." Participants indicated their agreement or nonagreement with each item. Need for achievement (nAch) and need for affiliation (nAff) scores were computed by counting the number of "true" responses given, after recoding oppositely worded items.

Need-satisfaction. Participants completed an 18-item psychological needs scale containing six items each for autonomy, competence, and relatedness (Sheldon \& Gunz, 2009; Sheldon, Cummins, \& Kamble, 2010). Each six-item scale contains three positively and three negatively worded items; Sheldon and Hilpert (2011) showed that the 18-item scale is underlain by autonomy, competence, and relatedness factors as well as by satisfaction and dissatisfaction factors. Participants were asked to "read each of the following items carefully, thinking about how it relates to your life, and then indicate how true it is for you" using a 1 (not at all) to 7 (very true) scale. Example autonomy, competence, and relatedness items are "I am free to do things my own way," "I do well even at the hard things," and "I feel a sense of contact with people who care for me, and whom I care for." For this research, we recoded the negative items and computed aggregate autonomy, competence, and relatedness satisfaction measures.

Positive affect. Participants were presented with five positive adjectives and asked "how (happy, pleased, joyful, relaxed, cheerful) do you feel right now?" A 1 (not at all) to 7 (very much) scale was employed, and the five responses were averaged.

\section{Results}

Table 1 presents descriptive statistics and correlations among the six primary study variables. Notably, the alpha reliability coefficients for the motive and need variables were quite low (.48 to .59), which may be due to participants' inexperience with or inattention to the lengthy "mass pretest" screening instrument. This constitutes a study limitation that needs to be addressed in other studies. However, we proceeded to test the study hypotheses anyway on the basis of the assumptions that the results would be attenuated yet unbiased indicators of population effects and that any effects, if found, would need to be replicated.

To examine unique associations and to test Hypotheses 1 and 2, we tested a path model corresponding to the left half of Figure 1 that specified paths from nAch to competence and from nAff to relatedness (Hypothesis 1a) and from autonomy, competence, and relatedness to positive affect (Hypothesis 2). The model also 
Table 1

Study 1: Descriptive Statistics and Correlations

\begin{tabular}{lccccccc}
\hline Variable & $M$ & $S D$ & nAch & nAff & Asat & Csat & Rsat \\
\hline nAch & 4.96 & 1.71 & .48 & & & & \\
nAff & 5.41 & 1.75 & .07 & .59 & & & \\
Asat & 1.02 & 1.72 & .15 & .13 & .52 & & \\
Csat & 0.69 & 1.75 & .27 & .07 & .04 & .56 & .43 \\
Rsat & 2.00 & 1.69 & .17 & .26 & .43 & .45 & .53 \\
PA & 5.10 & 1.25 & .12 & .15 & .31 & .29 & .40 \\
\hline
\end{tabular}

Note. $\quad \mathrm{nAch}=$ need for achievement; $\mathrm{nAff}=$ need for affiliation; Asat $=$ autonomy satisfaction; Csat $=$ competence satisfaction; Rsat $=$ relatedness satisfaction; $\mathrm{PA}=$ positive affect. For $r<.07, p<.05$. For $r<.09, p<.01$. Reliability coefficients appear on the diagonal.

included covariances between autonomy, competence, and relatedness, as these variables are typically positively correlated (Sheldon \& Hilpert, 2011). This model provided an excellent fit to the data (see Figure 2), with normed fit index (NFI; Tanaka, 1987), comparative fit index (CFI; Bentler, 1990) and goodness-of-fit index (GFI; Jöreskog \& Sörbom, 1993) = .98, .99, and .99, respectively, where values over .90 are taken to indicate good fit (Hu \& Bentler, 1998), and a root-mean residual (RMR) of .032, where values less than or equal to .05 are taken to indicate good fit (McDonald \& Ho, 2002). We also tested an alternative model setting $\mathrm{nAch}$ to predict relatedness and nAff to predict competence (i.e., opposite-theme pairings). This model fit considerably worse $(\mathrm{NFI}=.85, \mathrm{CFI}=.86, \mathrm{GFI}=.96, \mathrm{RMR}=.081)$ than the presented model.

Again, Hypothesis $1 \mathrm{~b}$ stated that competence mediates any nAch effects on SWB, and relatedness mediates any nAff effects on SWB. Although nAch and nAff were significantly correlated with SWB at the zero-order level (see Table 1), in the Figure 2 path model, no direct paths needed to be included from nAch and nAff to SWB. Regression mediation analyses (Baron \& Kenny, 1986; Sobel, 1982) showed that the effect of nAch on SWB was completely mediated by competence satisfaction (Sobel's $Z=6.13$, $p<.01$, with the nAch coefficient reduced from .12 to .05), and the effect of nAff on SWB was completely mediated by relatedness need-satisfaction (Sobel's $Z=6.85, p<.01$, with the nAff coefficient reduced from .15 to .05). This suggests that each

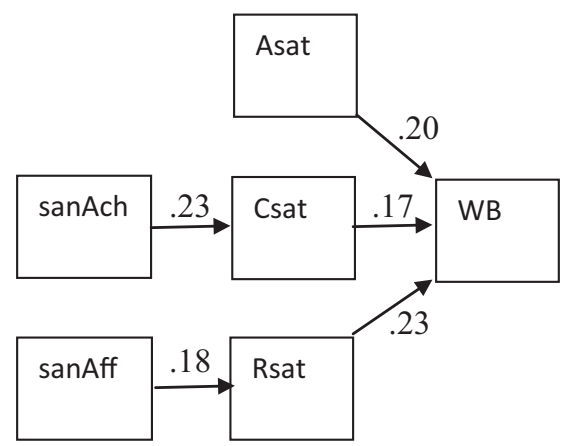

Figure 2. Study 1 path coefficients. Test-retest and error covariance coefficients are omitted. All coefficients are significant at $p<.05$. sanAch $=$ self-attributed need for achievment; sanAff $=$ self-attributed need for affiliation; Asat $=$ autonomy satisfaction; Csat $=$ competence satisfaction; Rsat $=$ relatedness satisfaction; $\mathrm{WB}=$ well-being. motive disposition arrives at its share of SWB via satisfaction of its own corresponding need.

To test Hypothesis 3, that the link between competence satisfaction and positive affect and the link between relatedness satisfaction and positive affect would not be moderated by achievement and affiliation motivation, respectively, we regressed positive affect upon (centered) achievement, affiliation, autonomy, competence, and relatedness at Step 1 and entered two product interaction terms (nAch $\times$ Competence, and nAff $\times$ Relatedness) at Step 2 . Neither interaction approached significance (both $p s>.20$ ), indicating that the associations of these two needs with well-being were unconditioned by participants' motive dispositions. This is consistent with the SDT proposition that everyone "needs" these experiences approximately to the same degree, even though people may vary on how much they "want" them.

\section{Brief Discussion}

Study 1 provided initial support for the research hypotheses, showing that participants high in the need for achievement tend to be having more competence experiences, and participants high in the need for affiliation tend to be having more relatedness experiences (Hypothesis 1a). Again, we assume that people develop basic motive dispositions at an early age, based on early positive experiences with "natural incentives," and that these motivational orientations thereafter suffice to keep these positive experiences coming (Atkinson, 1982). A new contribution of the present study is to suggest that competence and relatedness need-satisfaction are the natural incentives on which these two motive dispositions are based, a finding that logically connects MDT and SDT. Study 1 also replicated the typical finding that autonomy, competence, and relatedness uniquely predict positive mood and well-being (Hypothesis 2; Reis et al., 2000; Sheldon \& Krieger, 2007) and found that competence satisfaction mediated the nAch effects on positive affect and relatedness satisfaction mediated the nAff effects on positive affect (Hypothesis 1b). Finally, Study 1 found no interactions between motive dispositions and the corresponding satisfied need, in predicting positive affect (Hypothesis 3). Although these tests were only cross-sectional, the findings are consistent with SDT's universalist account of basic need effects and fail to support the conventional matching idea that those who "want" a certain experience more should benefit more when they "have" that experience.

In what ways might a matching perspective apply, then? Also, how do particular motive dispositions get from "wanting" to 
"having?" Study 2 was designed to address these questions by introducing a personal goal assessment to the mix. This allowed us to not only replicate the Hypotheses 1-3 findings but also to test Hypothesis 4, that participants feel more self-concordant motivation to pursue goals that match their motive dispositions. Again, Hypothesis 4 allows evaluation of an untested proposition of the self-concordance model: that rated self-concordance (i.e., pursuing one's goals for autonomous more than controlled reasons) indexes person-goal fit. If this is correct, then rated self-concordance should be highest when goal-content matches enduring motive dispositions.

\section{Study 2}

\section{Method}

Participants and procedure. Participants were 155 introductory psychology students, 50 men and 105 women, who took part to help fulfill a course requirement. They came to small group sessions to complete the paper-and-pencil questionnaire, which we hoped would ensure greater commitment and attentiveness.

\section{Measures.}

Motive dispositions. Participants completed the full versions of the achievement and affiliation scales of the Personality Research Form (Jackson, 1984). Each scale consisted of 16 true/false items, eight worded positively and eight negatively. Participants indicated their agreement or nonagreement with each item. nAch and nAff scores were computed by counting the number of "true" responses given, after appropriate recoding.

Need-satisfaction. Participants completed the same 18-item psychological needs scale as in Study 1. Participants were asked to "read each of the following items carefully, thinking about how it relates to your life, and then indicate how true it is for you" using a 1 (not at all) to 7 (very true) scale. Autonomy, competence, and relatedness need-satisfaction scores were computed by averaging the items, after recoding the negatively worded items.

Subjective well-being. Participants completed the 20-item Positive and Negative Affect Schedule (PANAS; Watson, Clark, $\&$ Tellegen, 1988) and completed the five-item Satisfaction with Life Scale (SWLS; Diener, Emmons, Larsen, \& Griffin, 1985). As in past self-concordance research, an aggregate SWB score (Die- ner, 1994; Sheldon \& Elliot, 1999) was computed by adding positive affect and life satisfaction and subtracting negative affect.

Goals. A mixed idiographic/nomothetic goal-assessment technique was used to assess participants' current strivings (Emmons, 1989). Participants read the following: "We are interested in what modern college students are striving to do in their lives. Please list five personal goals you want to pursue this semester. These can come from many different parts of your life, such as school, family, friends, relationships, health/fitness, or hobbies." After free listing five goals, participants were asked to categorize each goal as achievement ("trying to do your best at a job, in a class, in a sport, etc."), affiliation ("trying to have many friends/ acquaintances and a good social life"), intimacy ("trying to have close relationships, really connecting with others"), influence ("trying to have power, status, or control over others"), or other ("none of these"). Each participant was assigned an achievement goals score (number of goals identified as achievement) and an affiliation goals score (number of goals identified as affiliation or intimacy; the latter two categories were combined since both are relevant to relatedness need-satisfaction; see Footnote 2).

Participants also rated the self-concordance of their five goals, by rating why they strive for each in terms of external reasons ("because somebody else wants you to, or because the situation seems to compel it"), introjected reasons ("because you would feel ashamed, guilty, or anxious if you didn't"), identified reasons ("because you really believe that it's an important goal to have") and intrinsic reasons ("because of the enjoyment or stimulation the goal provides you"), using a 1 (not at all for this reason) to 5 (very much for this reason) scale (Sheldon \& Elliot, 1999; Sheldon \& Houser-Marko, 2001). As in previous research, an aggregate selfconcordance (or relative autonomy) score for the set of five goals was computed by adding the intrinsic and identified ratings and subtracting the introjected and external ratings.

\section{Results}

Descriptives and path model analyses. Table 2 contains descriptive statistics and correlations among all study variables. Notably, the reliability coefficients were considerably better in Study 2 than in Study 1. To examine unique associations and to simultaneously test Hypotheses 1a, 2, and 4, we tested a path

Table 2

Study 2: Descriptive Statistics and Correlations

\begin{tabular}{|c|c|c|c|c|c|c|c|c|c|c|c|}
\hline Variable & $M$ & $S D$ & nAch & nAff & \# Ach goals & \# Aff goals & Self-Concord & Asat & Csat & Rsat & WB \\
\hline nAch & 10.32 & 4.03 & .68 & & & & & & & & \\
\hline nAff & 10.75 & 4.43 & .50 & .81 & & & & & & & \\
\hline \# Ach goals & 2.05 & 1.01 & .04 & -.09 & - & & & & & & \\
\hline \# Aff goals & 1.78 & .79 & -.12 & .02 & -.43 & - & & & & & \\
\hline Self-Concord & 1.12 & 2.34 & .16 & .09 & .11 & -.01 & .80 & & & & \\
\hline Asat & 1.35 & 1.44 & .02 & -.01 & .05 & -.03 & .25 & .70 & & & \\
\hline Csat & 0.72 & 1.53 & .16 & .16 & -.06 & .00 & .26 & .33 & .73 & & \\
\hline Rsat & 1.61 & 1.53 & .10 & .15 & -.02 & -.02 & .25 & .41 & .34 & .72 & \\
\hline WB & 5.10 & 1.25 & .16 & .17 & .04 & -.02 & .41 & .46 & .63 & .52 & .93 \\
\hline
\end{tabular}

Note. $\quad \mathrm{nAch}=$ need for achievement nAff $=$ need for affiliation; \# Ach goals = number of achievement goals listed; \# Aff goals = number of affiliation goals listed; Asat $=$ autonomy satisfaction; Csat $=$ competence satisfaction; Rsat $=$ relatedness satisfaction; WB $=$ well-being. For $r<.16, p<.05$. For $r<.19, p<.01$. Reliability coefficients appear on the diagonal. 
model corresponding to the left half of Figure 1 that specified paths from achievement to competence and from affiliation to relatedness (Hypothesis 1a) and from autonomy, competence, and relatedness to SWB (Hypothesis 2; all variables were centered). This model also contained contained nAch $\times$ Number of Achievement Goals and nAff $\times$ Number of Affiliation Goals product interaction terms, which allowed us to test Hypothesis 4 (that these two interactions would significantly predict self-concordance; Hypothesis 3 was tested separately, by regressions, below). Finally, the concurrent portion of Hypothesis 5 could be tested in this model, by specifying a path from self-concordance to current SWB (Sheldon \& Kasser, 1995).

We did not include paths from nAch to number of achievement goals or from nAff to number of affiliation goals, as Hypothesis 4 specified that motive dispositions predict greater self-concordance when the goal-set as a whole is more motive-congruent and did not specify that motive dispositions predict adoption of a greater number of motive-congruent goals. However, we were prepared to add these two paths if necessary to represent the data (Job \& Brandstätter, 2009). We also did not include paths from the number of achievement or affiliation goals to self-concordance, expecting no main effects due to the predicted interaction. Once again, covariances were allowed between the three needs, and a path was specified from autonomy need satisfaction to selfconcordance.

This model provided a very good fit to the data (see Figure 3), with NFI $=.95, \mathrm{CFI}=.99, \mathrm{GFI}=.98$, and $\mathrm{RMR}=.053$. Consistent with Hypothesis 1a, nAch predicted competence and nAff predicted relatedness (although the former relation was only marginally significant, $p<.08$ ). Consistent with Hypothesis 2 and past research, all three needs predicted concurrent SWB; consistent with Hypothesis 4 , both the nAch $\times$ Number of Achievement Goals to self-concordance interaction path, and the nAff $\times$ Number of Affiliation Goals to self-concordance interaction path, were significant, indicating that participants' goal-sets were rated as more self-concordant the more goals they contained that matched the participant's motive dispositions. These interactions both involved crossover effects in which individuals lower in the disposition evidenced lower self-concordance the more achievement

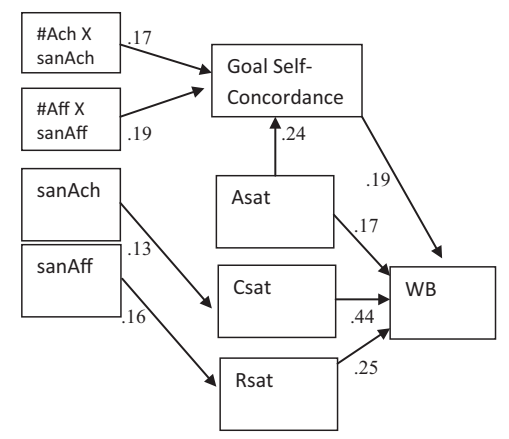

Figure 3. Study 2 path coefficients. Test-retest and error covariance coefficients are omitted. All coefficients are significant except sanAch to Csat $(p<.07)$. sanAch $=$ self-attributed need for achievement; sanAff $=$ self-attributed need for affiliation; Asat $=$ autonomy satisfaction; Csat $=$ competence satisfaction; Rsat $=$ relatedness satisfaction; $\mathrm{WB}=$ well-being. goals they listed and vice versa for individuals higher in the disposition. Finally, consistent with the concurrent part of Hypothesis 5, self-concordance was associated with concurrent SWB.

Interestingly, no paths needed to be included from nAch and nAff to the number of achievement or number of affiliation goals listed; thus, it appears that these motive dispositions do not necessarily affect how many motive-congruent goals participants freeselect but, rather, how participants feel about their set of goals depending on how many motive-congruent goals are present. Also, when paths were included from the number of achievement and the number of affiliation goal variables to self-concordance they were nonsignificant, suggesting that neither type of goal system feels more self-concordant than the other, on average.

We also considered two alternate models. In one, paths were specified from competence satisfaction to nAch and relatedness satisfaction to nAff, instead of vice versa (i.e., "having" was set to predict "wanting," rather than "wanting" set to predict "having"). This model did not fit the data as well, with RMR $=.094$ instead of .053. In a second alternative model, the nAch $\times$ Number of Achievement Goals and the nAff $\times$ Number of Affiliation Goals interactions were set to predict SWB instead of self-concordance. Are these interaction effects unique to self-concordance (persongoal fit), or do they also apply to the broader construct of SWB? In this model, neither interaction term was significant; that is, participants were not synergistically happier when they had listed more goals relevant to their motive dispositions. Thus, the predicted interaction effects do seem to be unique to the selfconcordance outcome.

Regression analyses. Regression mediation analyses were again used to test Hypothesis $1 \mathrm{~b}$. The effect of nAch on SWB was significantly mediated by competence satisfaction (Sobel's $Z=$ $2.40, p<.05$, with the coefficient reduced from .24 to .14 ), and the effect of nAff on SWB was significantly mediated by relatedness need-satisfaction (Sobel's $Z=2.61, p<.01$, with the coefficient reduced from .25 to .12). As in Study 1, this suggests that each motive disposition arrives at its share of SWB via satisfaction of its own corresponding need. We also conducted regression analyses to test Hypothesis 3, that there would be no Motive Disposition $\times$ Corresponding Need interactions in predicting SWB. Computed nAch $\times$ Competence and nAff $\times$ Relatedness product interaction terms were found to be nonsignificant when SWB was regressed on the two (centered) motive dispositions, the two (centered) need-satisfaction scores, and the two interaction product terms. These two interaction product terms were also nonsignificant when tested in the context of the full Figure 3 path model.

\section{Brief Discussion}

Study 2 first replicated the Study 1 effects regarding Hypothesis 1 , showing that the need for achievement predicts greater competence need satisfaction and the need for affiliation predicts greater relatedness need satisfaction (Hypothesis 1a). Again, chronic "wanting" seems to go with chronic "having," rather than with not having. This fits the characterization of motive dispositions as orientations that effectively guide participants' transactions in the world, at least within the relevant motivational domain. Hypothesis 2, that the three SDT needs each uniquely predict well-being, was again supported, and mediational analyses again suggest that nAch and nAff correlations with SWB are accounted for by 
competence and relatedness need-satisfaction, respectively (Hypothesis 1b). Hypothesis 3, that motive dispositions would not interact with current need-satisfaction to predict current SWB, was again confirmed, supporting SDT's universalist perspective.

In addition, Hypothesis 4 received its first test. Results indicate that for those high in the need for achievement, the more achievement goals they listed, the higher the self-concordance ratings. For those high in the need for affiliation, the more relationship goals they listed, the higher the self-concordance ratings. These findings provide a new type of support for the self-concordance model's presumption that the relative autonomy measure indexes persongoal fit (Sheldon \& Cooper, 2008). Again, the two motive dispositions did not predict a larger number of corresponding goals being listed; achievers and affiliators both have multiple roles and constraints to satisfy and apparently do not automatically load up on motive-relevant goals. However, if for some other reason they end up with more motive-relevant goals in their system, they feel more self-concordant.

Although Study 2 provided both a replication and extension of Study 1 to goals, Study 2 was still only cross-sectional. A longitudinal study would provide much stronger support for the dynamic hypotheses being tested in this research. Do self-concordant goals, once set, actually produce more of the desired experience for a particular motive disposition? This involves testing the sequence of relationships specified by Hypothesis 5: that selfconcordance predicts longitudinal goal-attainment, which, in turn, predicts enhanced need-satisfaction and thus enhanced SWB over time (Sheldon \& Elliot, 1999; Sheldon \& Krieger, 2007). To address this dynamic portion of the model, we conducted a multiple-wave study that let us examine goal striving effects upon changes in psychological state.

Study 3 was also an experimental study in which participants were randomly assigned to pursue either a set of achievement goals or a set of relationship goals. Random assignment was important because Study 2 might suffer from self-selection effects in that participants chose themselves what proportion of achievement or affiliation goals to list (although motive dispositions themselves were unrelated to these proportions). By randomly assigning goal content, it was possible to unconfound participants' feelings of self-concordance from their idiographic goal-setting preferences, and it was possible to mimic a work or group setting in which certain goals are prescribed or not prescribed, to the individual's benefit or detriment.

In sum, in Study 3, we endeavored to test all five study hypotheses simultaneously, using a strong longitudinal experimental methodology. Study 3 also included a large $N(>500)$, enabling very good power for detecting interactions. If Hypothesis 3 (that needs and motives do not interact to predict SWB) continues to be supported both with a large $N$ and via both cross-sectional and longitudinal tests, then we might begin to be persuaded to "accept the null" in this case.

\section{Study 3}

\section{Method}

Participants and procedure. Participants were 592 students in a social psychology class, 205 men and 335 women (12 did not report gender), who completed all questionnaires for extra credit.
The data were collected over two consecutive semesters and were aggregated after no semester differences (spring vs. fall 2009) were found on any of the Time 1 variables. Students completed three in-class questionnaires, held approximately 6 weeks apart. In the first questionnaire, well-being, need satisfaction, motive dispositions, and semester goals (either in assigned achievement or assigned relationship categories) were assessed. In the middle questionnaire, current goal attainment was assessed, and in the final questionnaire, goal attainment, need-satisfaction, and wellbeing were assessed. Analyses focus on the beginning and end of semester data, with the goal-attainment variable being derived from the middle and end-of-semester ratings (see Figure 1).

\section{Measures.}

Motive dispositions, well-being, and needs. Need for achievement, need for affiliation, SWB, and current autonomy, competence, and relatedness need-satisfaction were all assessed with the same scales and items as in Study 2, except that the SWB and need-satisfaction questions were all framed in terms of "right now in my life," so that longitudinal change could be more readily detected.

Goal assignment and assessment. Midway through the first questionnaire, participants read the following:

In this part of the study, we are interested in what modern college students are striving to do in their lives. Below, we will ask you to list three personal goals that you will be pursuing over the semester. These can be goals you were already going to pursue, or goals you just now come up with. Please take this task seriously, because we will be asking you about these goals several times during the semester!

Participants then read, "before you list your three goals, there is one thing to keep in mind." Achievement goal participants then read, "we'd like you to list a particular type of goal—concerning achievement and performance. Research indicates that college students do not focus enough energy in this domain, and so we would like all three of your goals to be about achievement." Affiliation goal participants instead read, "We'd like you list a particular type of goal-concerning relationships and connections. Research indicates that college students do not focus enough energy in this domain, and so we would like all three of your goals to be about relationships." After writing down three goals, students made a copy of their goal sheet to keep. Two hundred eighty participants were assigned to the achievement goal condition, and 272 participants to the affiliation goal condition.

Manipulation check. As a check following the goal-listing task, participants were given the same goal categorization item used in Study 2, so that a count of the number of achievement and relationship goals could be made. Preliminary analyses revealed that assigned achievement goal participants listed 1.93 (out of 3) achievement goals, on average, and only .45 relationship goals; relationship goal participants listed 2.27 relationship goals and only .68 achievement goals (both $p$ s $<.001$ ). Thus, participants largely followed the instructions, although some participants departed from the request for some goals. Results were essentially unchanged when the sample was confined to participants who reported listing all three goals of the assigned type, and thus, we retained the full sample.

Self-concordance. After the Time 1 categorization task, participants were asked to rate why they would be pursuing their three goals, in terms of the same four reasons (external, introjected, 
identified, intrinsic) employed in Study 2 and in earlier research (Sheldon \& Elliot, 1999; Sheldon \& Houser-Marko, 2001). An aggregate self-concordance score was computed in the same way as before by summing the intrinsic and identified ratings and subtracting the external and introjected ratings.

Goal attainment. At the middle and end of the semester, participants rated current progress (How well are you doing at each goal?) on their three goals, using a 1 (not at all well) to 5 (extremely well) scale and rated current attainment (How well are you attaining each goal?), using a little attainment to much attainment scale. An aggregate semester goal-attainment variable was computed by averaging the 12 responses.

\section{Results}

Table 3 contains descriptive statistics and correlations among all study variables. Notably, the reliability coefficients again were considerably better in this study compared with Study 1 . In order to examine unique associations and to simultaneously test the hypotheses, we constructed a path equation model corresponding to the entirety of Figure 1 that specified paths from nAch to Time 1 competence; from nAff to Time 1 relatedness (Hypothesis 1a); and from Time 1 autonomy, competence, and relatedness to Time 1 SWB (Hypothesis 2). The model also contained nAch $\times$ Assigned Goal Condition and nAff $\times$ Assigned Goal Condition product interaction terms, which allowed us to test Hypothesis 4 (that these two interactions would significantly predict selfconcordance; Hypotheses $1 \mathrm{~b}$ and 3 are tested by regression analyses below). Finally, the complete temporal sequence specified by Hypothesis 5 was tested in this model by specifying paths from self-concordance to goal attainment, which, in turn, predicted enhanced need-satisfaction, which, in turn, predicted enhanced well-being (Sheldon \& Elliot, 1999).

So that the latter part of the model would be focused on longitudinal change in the relevant variables, test-retest paths were specified from the three Time 1 need-satisfaction variables to the corresponding Time 3 need-satisfaction variables, as was a path from Time 1 SWB to Time 3 SWB. In addition, a path was allowed from self-concordance to Time $1 \mathrm{SWB}$, as in Study 2 and consistent with past research (Sheldon \& Kasser, 1995), and a path was allowed between Time 1 SWB and later goal-attainment, as positive well-being has been shown to predict a wide range of positive functional and performance outcomes (Lyubomirsky, King, \& Diener, 2005). Once again, covariances were allowed between the three needs, and a path was specified from autonomy satisfaction to self-concordance.

This model provided a good fit to the data (see Figure 4), with $\mathrm{NFI}=.96, \mathrm{CFI}=.98, \mathrm{GFI}=.96$, and RMR $=.061$. Consistent with Hypothesis 1a, nAch predicted competence and nAff predicted relatedness. Consistent with Hypothesis 2 and past research, all three needs predicted concurrent SWB at Time 1, and changes in the three needs also predicted change in SWB at Time 3; consistent with Hypothesis 4, both the nAch $\times$ Assigned Achievement Goals to self-concordance interaction path and the nAff $\times$ Assigned Affiliation Goals to self-concordance interaction path were significant, indicating that participants' goal-sets were rated as more self-concordant when they were assigned to list goals that match their motive dispositions. In particular, participants in the assigned achievement goal condition reported more selfconcordant motivation if they were high in $\mathrm{nAch}$ (in this condition, nAch predicted self-concordance at $\beta=.30, p<.001$, compared with $\beta=.07, n s$, for nAff), and in the assigned affiliation goal condition, participants reported more self-concordant motivation if they were high in nAff (in this condition, nAff predicted selfconcordance at $\beta=.20, p<.001$, compared with $\beta=.03$, ns, for $\mathrm{nAch})$. In addition, the direct paths from nAch and nAff to selfconcordance were significant in Study 3.

Exploratory analyses indicated that model fit could be slightly improved (to NFI $=.97, \mathrm{CFI}=.98, \mathrm{GFI}=.97, \mathrm{RMR}=.051$ ) if assigned goal type were allowed to predict self-concordance (participants felt significantly less self-concordant regarding assigned achievement goals), if nAch and nAff were allowed to correlate with one another, and if nAch and nAff were allowed to directly predict Time 1 SWB (these paths are not portrayed in Figure 4). Thus, although the direct paths from nAch and nAff to Time 1 SWB were nonsignificant in the structural models of Studies 1 and 2, they remained significant in Study 3.

Regression analyses. Still, supplementary regression mediation analyses to test Hypothesis $1 \mathrm{~b}$ again showed that the effect of

Table 3

Study 3: Descriptive Statistics and Correlations

\begin{tabular}{|c|c|c|c|c|c|c|c|c|c|c|c|c|c|c|}
\hline Variable & $M$ & $S D$ & 1 & 2 & 3 & 4 & 5 & 6 & 7 & 8 & 9 & 10 & 11 & 12 \\
\hline 1. nAch & 9.98 & 3.28 & .70 & & & & & & & & & & & \\
\hline 2. nAff & 10.98 & 3.43 & .13 & .80 & & & & & & & & & & \\
\hline 3. T1Asat & 1.06 & 1.34 & .26 & .04 & .66 & & & & & & & & & \\
\hline 4. T1Csat & 0.70 & 1.43 & .22 & .26 & .41 & .71 & & & & & & & & \\
\hline 5. T1Rsat & 1.49 & 1.51 & .35 & .03 & .41 & .41 & .72 & & & & & & & \\
\hline 6. T1WB & 4.83 & 1.47 & .39 & .24 & .51 & .55 & .57 & .88 & & & & & & \\
\hline 7. Self-Concord & 3.53 & 2.51 & .15 & .17 & .17 & .24 & .20 & .29 & .73 & & & & & \\
\hline 8. Attain & 3.42 & 0.67 & .24 & .18 & .20 & .27 & .21 & .35 & .20 & .85 & & & & \\
\hline 9. T3Asat & 1.10 & 1.48 & .19 & .05 & .40 & .32 & .29 & .38 & .24 & .23 & .78 & & & \\
\hline 10. T3Csat & 0.86 & 1.41 & .23 & .07 & .25 & .27 & .42 & .38 & .18 & .24 & .50 & .79 & & \\
\hline 11. T3Rsat & 1.57 & 1.52 & .21 & .24 & .33 & .45 & .32 & .42 & .21 & .36 & .47 & .44 & .78 & \\
\hline 12. T3WB & 4.76 & 1.68 & .31 & .21 & .34 & .41 & .37 & .58 & .21 & .34 & .48 & .48 & .59 & .91 \\
\hline
\end{tabular}

Note. $\mathrm{nAch}=$ number of achievement goals listed; $\mathrm{nAff}=$ number of affiliation goals listed; Asat $=$ autonomy satisfaction; Csat $=$ competence satisfaction; Rsat $=$ relatedness satisfaction; WB = well-being. For $r<.08, p<.05$. For $r<.11, p<.01$. Reliability coefficients appear on the diagonal. 


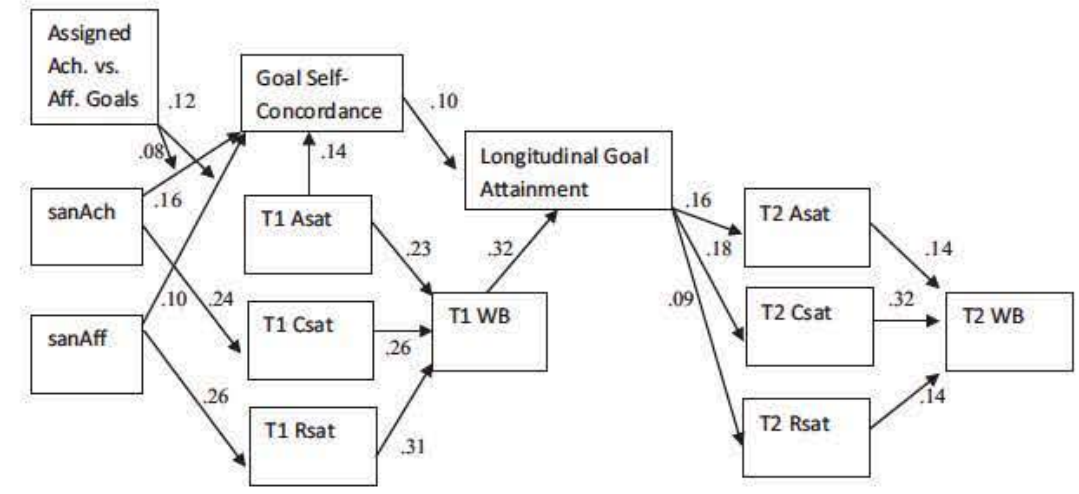

Figure 4. Study 3 path coefficients. Test-retest and error covariance coefficients are omitted. All coefficients are significant at $p<.05$. sanAch $=$ self-attributed need for achievement; sanAff $=$ self-attributed need for affiliation; Asat $=$ autonomy satisfaction; Csat $=$ competence satisfaction; Rsat $=$ relatedness satisfaction; $\mathrm{WB}=$ well-being.

nAch on SWB was significantly (if not completely) mediated by competence satisfaction (Sobel's $Z=5.73, p<.01$ ), and the effect of nAff on SWB was significantly (if not completely) mediated by relatedness need-satisfaction (Sobel's $Z=7.34$, $p<.01)$. This again suggests that each motive disposition arrives at its share of SWB largely via satisfaction of its own corresponding need. We also used regression analyses to test Hypothesis 3, in two different ways. First, Time 1 SWB was regressed on (centered) nAch, nAff, Time 1 competence satisfaction, Time 1 relatedness need satisfaction, and two product interaction terms $(\mathrm{nAch} \times$ Competence and $\mathrm{nAff} \times$ Relatedness). Neither interaction approached significance. Second, Time 2 SWB was regressed on nAch, nAff, Time 1 SWB, Time 1 competence and relatedness, Time 2 competence and relatedness, and two product terms (nAch $\times$ Time 2 Competence and nAff $\times$ Time 2 Relatedness). Again, neither interaction approached significance, indicating that changes in competence satisfaction do not disproportionately affect the well-being of those high in $\mathrm{nAch}$, and changes in relatedness satisfaction do not disproportionately affect the well-being of those high in nAff. Also, when the cross-sectional and longitudinal interaction effects were examined in the context of the full model, they were also nonsignificant (and thus they are not included in Figure 4). Thus, "null" Hypothesis 3 was once again supported in Study 3.

There are a variety of other possible moderator effects that might be examined with the Study 3 data. Do participants initially low in competence or relatedness need-satisfaction get more SWB benefit from attaining achievement or affiliation goals, respectively (i.e., Initial Need-Satisfaction $\times$ Attainment $\times$ Goal Type three-way interactions), and might such effects be moderated by motive dispositions (i.e., four-way interactions)? Do achievement goals, when attained, produce greater boosts in competence satisfaction than when affiliation goals are attained (i.e., Goal Type $\times$ Attainment $\times$ Change In Satisfaction three-way interactions), and might such effects be moderated by motive dispositions (i.e., four-way interactions). However, a systematic exploration of these possibilities revealed no higher order interactions in these data, beyond those represented in Figure 4.

\section{Brief Discussion}

Study 3 replicated the cross-sectional results of Studies 1 and 2 (Hypotheses 1-4) and provided support for the set of longitudinal relations specified by Hypothesis 5. Overall, the data provided a reasonably good fit for the entire complex model depicted in Figure 1. Further confidence in the model is warranted because Study 3 included an experimental component with random assignment; thus, the relations among goal, motivation, and well-being variables apparently represent more than self-selection effects. In particular, participants in the assigned achievement goal condition reported more self-concordant motivation if they were high in $\mathrm{nAch}$, and in the assigned affiliation goal condition, participants reported more self-concordant motivation if they were high in nAff. Initial self-concordance, in turn, predicted greater longitudinal attainment, which was associated with enhanced needsatisfaction and well-being.

\section{Study 4}

Astute readers will have noticed an important limitation of the data presented so far: The motives for achievement and affiliation have been measured only by self-report (i.e., via the PRF). Although the PRF is often used in contemporary motive disposition research, the classic theorizing of McClelland, Atkinson, and Murray concerned primarily nonconscious motives, which could be measured only indirectly, via projective tests such as the Thematic Apperception Test (Murray, 1943) or the Picture Story Exercise (see Schultheiss \& Pang, 2007; Winter, 1999). In other words, the PRF measures explicit motives (self-attributed motives, according to McClelland et al., 1989), which can be distinguished from implicit or nonconscious motives (McClelland et al., 1989). McClelland et al. (1989) and Brunstein (2008) stated that implicit and explicit motives differ in terms of their developmental history, with implicit motives developed earlier in life on the basis of affective experiences, whereas explicit motives are cognitionbased and are learned later when the self-concept develops. Also, implicit motives are incited by activity-related incentives (e.g., enjoyment of activity, feeling of competence), whereas explicit 
motives are incited by purpose-related incentives (e.g., praise, positive evaluation by others; see Brunstein, 2008, for a discussion of other differences between the two types of motive measures).

Indeed, recent research on motive-incongruence have showed that explicit motives are not necessarily in accordance with the corresponding implicit motives (Baumann, Kaschel, \& Kuhl, 2005; Brunstein, 2008; Kehr, 2004; Langan-Fox, Sankey, \& Canty, 2009; Schüler, 2010; Thrash, Elliot, \& Schultheiss, 2007) and that they can be associated with different types of outcomes (McClelland et al., 1989). Given these important differences between explicit and implicit motives, it seemed essential to examine whether the basic results of Studies 1-3 generalize to implicit measures. Because our theorizing is based on motive disposition theory without reference to the implicit/explicit issue, we predicted that they would. Both types of measure represent enduring motivational orientations that guide people through life in a certain way, and the hypothesis that "wanting" a need more tends to result in more corresponding need satisfaction (Hypothesis 1a) should be equally true for explicit and implicit motives. Also, any association of a motive disposition with SWB should be mediated by corresponding need-satisfaction (Hypothesis 1b), and neither the implicit nor the explicit measures of motive dispositions should moderate need-satisfaction effects on SWB (Hypothesis 3).

To test these hypotheses, in Study 4 we administered the Picture Story Exercise task (Schultheiss \& Pang, 2007), a measure of implicit motives, in addition to the PRF, SWB, and basic needsatisfaction measures. After replicating the earlier results with the PRF, we predicted that PSE implicit nAch would be associated with competence need-satisfaction, and PSE implicit nAff would be associated with relatedness need-satisfaction (H1a) and that any effects of these measures on SWB would be mediated by the corresponding satisfaction variable (H1b). Also, we predicted that the predicted need-satisfaction effects on SWB (H2) would again be unmoderated by motive dispositions (H3). In other words, we expected the effects of need satisfaction on well-being to be universal in the sense of not being influenced by how much participants "want" a particular need, whether the wanting is assessed implicitly (PSE) or explicitly (PRF). Hypotheses 4 and 5 were not tested in Study 4, as the study did not include a goal assessment.

Other innovations of Study 4 include the fact that we used a different nationality of sample (Swiss students rather than U.S. students) and used a somewhat different questionnaire to assess basic need satisfaction. If our hypotheses are supported despite these variations, then the robustness and generalizability of our results will be better established.

\section{Method}

Participants and procedure. Three linked web surveys were administered to students of an introductory course on psychology; the assessment was broken down into three parts to reduce participant fatigue and for methodological reasons described below. The students were invited to take part in a study named "How do students experience their college days?" in return for extra course credit. Two hundred thirty individuals agreed to participate in the study. The first survey contained the explicit motive measure and the assessment of the satisfaction of the basic needs for competence and relatedness. The implicit motive measure was adminis- tered in a second survey, because it is time consuming and demanding (30 min of writing plus instructions) and because it is very sensitive toward motive-arousing effects that might be induced by other questionnaires and the setting of data collection (cf. Lundy, 1988; Schultheiss \& Pang, 2007). The third survey assessed positive and negative affect and life satisfaction several weeks later; we decided to administer these "outcome" variables on a third occasion to separate them from the two motive assessment occasions. The data of the three web surveys were matched by codes in order to guarantee anonymity. One hundred four female and 28 male participants, with a mean age of 22.13 years $(S D=5.15)$, completed all three parts of the survey, and their data sets were considered in the following analyses.

\section{Measures.}

Implicit motives. To measure implicit motives the Picture Story Exercise (PSE; cf. McClelland et al., 1989; Schultheiss \& Pang, 2007) was used. Following the principles of Murrays' Thematic Apperception Test (TAT) procedure (Murray, 1943), pictures were shown, and participants were asked to invent and write down imaginative stories that were then coded by the experimenters regarding achievement and affiliation imagery using sophisticated coding systems. In the present study, we followed the suggestion of Schultheiss and Pang (2007) and used six pictures (couple by river, nightclub scene, women in laboratory, ship captain, trapeze artists, boxer) that were presented for $15 \mathrm{~s}$ at the screen, after which participants wrote a story directly into the computer. After 4 min, participants were told to finish their story, and 1 min later, the next picture was presented. Winter's (1994) running text scoring system, which is psychometrically well validated, was used to code for the implicit achievement (PSE nAch) and affiliation motive (PSE nAff). The scorer was experienced and established percentage agreement of $94 \%$ with materials prescored by Winter (1994).

Explicit motives. Participants filled in the achievement and affiliation scales of the German Version of the Personality Research Form (Jackson, 1984; German Version: Stumpf, Angleitner, Wieck, Jackson, \& Beloch-Till, 1985). Each scale consists of 16 items for which participants indicated their agreement or nonagreement. Explicit achievement motive (PRF nAch) and explicit affiliation motive (PRF nAff) scores were computed by summing up all items that participants agreed with (after recoding reversed items).

Need-satisfaction. Participants completed the Basic Need Satisfaction in General Scale (e.g., Gagné, 2003; Kashdan, Julian, Merritt, \& Uswatte, 2006). Participants responded to items of the autonomy scale (e.g., I feel like I am free to decide for myself how to live my life), the competence subscale (e.g., I have been able to learn interesting new skills recently), and the relatedness subscale (e.g., I consider the people I regularly interact with to be my friends) using a rating scale from 1 (not at all true) to 7 (very true). A mean score for each need was computed.

Subjective well-being. As in Study 2 and in previous research (Diener et al., 1985), subjective well-being was assessed by adding the positive affect score of the PANAS (Watson et al., 1988; German version: Krohne, Egloff, Kohlmann, \& Tausch, 1996) and the life-satisfaction score of the SWLS (Diener et al., 1985; German version: Lettner, Sölva, \& Baumann, 1996) and subtracting negative affect (PANAS). All variables were centered before aggregation. 


\section{Results}

Preliminary analyses. Participants who did not complete all three surveys did not differ in any of the initial assessment variables. Men and women did not differ in their implicit or explicit motive scores or in their need satisfaction, subjective well-being, and flow experience. Neither participants' sex nor age influenced the results reported below.

The achievement and affiliation motive scores of the Picture Story Exercise were significantly correlated with the number of words in the imaginative stories (PSE nAch $r=.36, p<.001$; PSE nAff $r=.56, p<.001)$. In order to remove the influence of verbal fluency from the motive measures, we residualized motive scores for word count and used the residual scores in all analyses that we further report (for more on this procedure, see Schultheiss \& Pang, 2007).

Descriptive statistics. Table 4 presents descriptive statistics and correlations among the variables of Study 4. As can be seen, felt autonomy, competence and relatedness were highly significantly correlated with each other ( $r$ s between .44 and $.45, p \mathrm{~s}<$ .001 ) and with subjective well-being ( $r$ s between .42 and $.54, p s<$ .001). In accordance with typical findings (e.g., McClelland et al., 1989), the implicit and explicit motive measures were unrelated and show different relationships to other variables.

Substantive results. Below we present the results for Hypotheses $1 \mathrm{a}, 1 \mathrm{~b}, 2$, and 3 , first using the PRF measures, then the PSE measures.

Hypothesis 1a. First we regressed relatedness needsatisfaction upon the PRF nAch and PRF nAff scales. As hypothesized PRF nAff predicted need for relatedness satisfaction significantly $(\beta=.66, p<.001)$, whereas the effect of PRF nAch was not significant $(\beta=.05, p>.30)$, overall model $R^{2}=.44, F(2$, $201)=77.24, p<.001$. Second, we regressed competence needsatisfaction upon the PRF nAch and PRF nAff and found, as expected, that PRF nAch predicted need for competence satisfaction $(\beta=.31, p<.001)$. Unexpectedly, PRF nAff also predicted competence satisfaction $(\beta=.30, p<.001)$, overall model $R^{2}=$ $.16, F(2,201)=21.07, p<.001$. In sum, consistent with Studies $1-3$, each motive disposition predicted its corresponding need (i.e., from "wanting" to "having"), although in this study nAff also predicted felt competence.

Next we conducted the same two analyses using PSE nAch and PSE nAff. In accordance with our hypothesis, relatedness satisfac- tion was significantly predicted by PSE nAff $(\beta=.16, p<.05)$ but not by PSE nAch $(\beta=-.04, p>.50)$, overall model $R^{2}=.02$, $F(2,201)=2.60, p<.05$. However, neither nAch nor nAff predicted competence satisfaction. Supplemental analyses with the five scoring subcategories of the PSE nAch measure revealed that some categories-e.g., positive evaluation of performance $(\beta=$ $.14, p<.05)$, overall model $R^{2}=.03, F(2,201)=3.25, p<$ .05 - predicted competence satisfaction better than others (e.g., mention of winning or competing with others; failure). Still, it must be concluded that the PSE measures are more weakly associated with need-satisfaction than the PRF measures. It is possible that the separation of time between the PSE administration and the need-satisfaction administration explains the weaker results for the PSE; this is discussed below.

Hypothesis 1 b. Hypothesis $1 \mathrm{~b}$ stated that motive disposition effects upon SWB, where they emerged, would be mediated by the corresponding need-satisfaction variable. Only one such zeroorder association emerged, between PRF nAff and SWB (PRF nAch and PSE nAch and PSE nAff were unrelated to SWB). In order to test whether the PRF nAff relationship with SWB was mediated by relatedness, we conducted a regression mediation analysis, proposed by Baron and Kenny (1986). The analysis showed that the PRF nAff coefficient was reduced from .41 to .23 (Sobel's $Z=5.81, S E=0.11, p<.001$ ), indicating significant partial mediation.

Hypothesis 2. In accordance with Hypothesis 2, the correlation analyses presented in Table 4 revealed significant associations between competence and relatedness need-satisfaction and subjective well-being. When controlling for the common variance of need for competence and relatedness by regressing subjective well-being on both needs simultaneously, the significant effects remained: competence $\beta=.41, p<.001$; relatedness $\beta=.24, p<$ .001 ; overall model $R^{2}=.32, F(2,201)=46.27, p<.001$.

Hypothesis 3. In order to test our hypotheses that neither explicit nor implicit motive dispositions interact with corresponding need-satisfactions to predict subjective well-being, we conducted a series of hierarchical regression analyses in which we first entered the motive and the corresponding need satisfaction as a first step into the regression analysis, followed by the interaction of both variables as a second step (all variables were centered). The results of these analyses are summed up in Table 5 . As can be seen, none of the analyses revealed a significant interaction of a motive

Table 4

Study 4: Descriptive Statistics and Correlations

\begin{tabular}{|c|c|c|c|c|c|c|c|c|c|c|}
\hline Variable & $M$ & $S D$ & 1 & 2 & 3 & 4 & 5 & 6 & 7 & 8 \\
\hline 1. PSE nAch & .01 & 1.0 & - & & & & & & & \\
\hline 2. PSE nAff & -.03 & .89 & .17 & - & & & & & & \\
\hline 3. PRF nAch & 9.99 & 2.44 & .01 & .03 & .74 & & & & & \\
\hline 4. PRF nAff & 11.93 & 2.96 & -.10 & .09 & -.04 & .73 & & & & \\
\hline 5. Asat & 5.38 & 1.0 & .11 & .01 & .21 & .31 & .71 & & & \\
\hline 6. Csat & 4.98 & 1.0 & .07 & .11 & .30 & .28 & .55 & .76 & & \\
\hline 7. Rsat & 5.65 & .83 & -.01 & .15 & .03 & .66 & .48 & .44 & .78 & \\
\hline 8. SWB & 6.49 & 1.96 & .09 & .06 & .12 & .41 & .49 & .52 & .42 & .70 \\
\hline
\end{tabular}

Note. $\quad$ PSE $=$ picture story exercise; $\mathrm{nAff}=$ need for affiliation; $\mathrm{nAch}=$ need for achievement; PRF $=$ personality research form; Asat $=$ autonomy satisfaction; Csat $=$ competence satisfaction; Rsat $=$ relatedness satisfaction; SWB $=$ subjective well-being. For $r<.17, p<.05$. For $r<.28, p<.001$. The implicit motive scores are standardized residuals (corrected for word count, see above). Reliability coefficients appear on the diagonal. 
Table 5

Study 4: Results of the Hierarchical Regression Analyses of Subjective Well-Being on Explicit (PRF) and Implicit (PSE) Motives and Need Satisfaction and the Motive $\times$ Need Satisfaction Interaction

\begin{tabular}{|c|c|c|c|c|c|c|c|c|}
\hline \multicolumn{5}{|c|}{ Main effects } & \multicolumn{4}{|c|}{ Interaction effects } \\
\hline$b^{\mathrm{a}}$ of need & $b^{\mathrm{a}}$ of motive & $\Delta R^{2}$ & $d f$ & $\Delta F$ & $b^{\mathrm{a}}$ of interaction & $\Delta R^{2}$ & $d f$ & $\Delta F$ \\
\hline Csat: $.53^{* * * *}$ & PRF nAch: -.03 & .27 & 2,199 & $36.94^{* * * *}$ & 01 & .00 & 1,198 & 0.03 \\
\hline Rsat: $.26^{* * *}$ & PRF nAff: $.22^{*}$ & .21 & 2,199 & $26.32^{* * * *}$ & -.04 & .00 & 1,198 & 0.29 \\
\hline Csat: $52^{* * * *}$ & PSE nAch: .06 & .27 & 2,199 & $37.37^{* * * *}$ & .10 & .00 & 1,198 & 2.5 \\
\hline Rsat: $.42^{* * * * *}$ & PSE nAff: -.00 & .18 & 2,199 & $21.73^{* * * *}$ & -.00 & .00 & 1,198 & 0.00 \\
\hline
\end{tabular}

Note. $\mathrm{PRF}=$ personality research form; $\mathrm{PSE}=$ picture story exercise Csat $=$ competence satisfaction; Rsat $=$ relatedness satisfaction. ${ }^{*} p<.05$. ${ }^{* * *} p<.01$. **** $p<.001$.

and the corresponding need satisfaction, regardless of whether explicit or implicit motives were entered. As also can be seen, need for relatedness and competence satisfaction, respectively, remained significant predictors of well-being in all analyses.

\section{Brief Discussion}

Study 4 replicated results found in the first three studies, again using the PRF. Thus, PRF nAch predicted competence satisfaction, and PRF nAff predicted relatedness satisfaction (Hypothesis 1a). Once again, these two needs predicted SWB (Hypothesis 2), and relatedness mediated the nAff effects on SWB (Hypothesis 1b). Finally, in accordance with Hypothesis 3, the explicit motives once again did not interact with corresponding need-satisfactions to predict subjective well-being.

As a new contribution, Study 4 replicated all of these findings using implicit motive disposition measures based on the PSE, including the finding that motive dispositions do not moderate need-satisfaction effects upon SWB. However, there was one failure to replicate, namely, that the PSE nAch scale did not predict competence need-satisfaction. This may be due to the measures being separated in time; competence need-satisfaction could have changed between the first and second assessments. It may also be that implicit motive dispositions are simply not as strongly related to subjective (self-attributed) satisfaction, such that the "wanting to having" relationship is weaker when the measures cross the implicit/explicit divide. Use of an implicit need-satisfaction measure might strengthen the relationship.

\section{General Discussion}

As discussed at the beginning of this article, a variety of need theories and perspectives exist within the literature, and they employ widely varying definitions and assumptions concerning the nature of psychological needs. For the most part, these theories are used and applied independently of each other, and the differences between them are ignored or not addressed. In this research we combined MDT, a prominent theory of psychological needs focusing on needs as acquired individual differences in preferences for certain natural incentives, and SDT, a prominent theory of psychological needs focusing on needs as inherited and speciestypical requirements for certain basic experiences. Although the two theories seem incompatible on the surface, because of their individual differences versus universalist foci and their behavioral motives versus experiential requirements foci, more careful con- sideration suggests that they may be addressing two different sides of the same phenomena and that they can peacefully coexist within the same logical structure. In a nutshell, SDT may specify the basic psychological needs that give natural incentives their appeal, needs perhaps required by everyone, whereas MDT may identify individual differences in desires for these same needs, presumably acquired on the basis of differential learning histories or developmental trajectories.

And indeed, this research found that predictions deriving from both theories could be accommodated within the same conceptual and statistical model. In brief, in all four studies, the motive dispositions to seek achievement and affiliation were associated with satisfaction of the corresponding type of need specified by SDT, namely, competence and relatedness (Hypothesis 1a). Thus, "wanting more" does appear to correspond with "having more," at least when wanting is construed as a chronic individual disposition to prefer certain types of satisfaction or natural incentives.

Independent of these individual difference findings, "having" (or increasing) the three needs predicted well-being and enhanced well-being in all three studies (Hypothesis 2), again supporting the SDT presumption that these are universal psychological needs that may exist as part of a shared human nature (Deci \& Ryan, 1985, 2000, 2008). Indeed, associated feelings of competence mediated or explained every relationship of nAch with SWB, and similarly for relatedness mediating nAff's relationships with SWB (Hypothesis 1b). Again, wanting "X" may lead to having "X," which, when " $\mathrm{X}$ " is really a need, accounts for the well-being benefits of such wanting.

Further supporting SDT's universalist or common-process presumption, "wanting" did not interact with "having" to predict well-being and increases in well-being (Hypothesis 3): Those who seem not to want a particular need (i.e., they are low on that motive disposition according to the PRF or PSE) gained just as much benefit from having that need met as those who claim to want the need. In other words, feeling competent or feeling related had the same effects on SWB regardless of the person's motives. To use an analogy, these two experiences may be like physical "vitamins" that everybody needs, to the same amount (per unit bodyweight), such as Vitamin C. People may differ in whether they eat oranges, lemons, or grapefruit, or whether they eat citrus fruits at all; still, they all have the same underlying need and benefit just as much by getting it met. The lack of any support for a "motive matching" hypothesis, despite ample power and opportunity to detect such interactions, also implies that wanting and needing can be some- 
what disconnected; people might want more than they really need (e.g., a high achiever who sacrifices family and balance for extra competence) or not want as much as they really need (e.g., this same person might claim not to want relationships, although he or she really does need them).

However, these studies do support a motive-based matching hypothesis in one important way, in that Study 2 and 3 participants who chose or were assigned to pursue goals that matched their primary motive disposition felt greater self-concordance in pursuing those goals (Hypothesis 4). A noteworthy aspect of these moderator findings is that they provide a new type of support for the self-concordance model (Sheldon, 2004), which assumes that autonomous, relative to controlled, goal pursuit indexes deep person-goal fit; the current data are quite consistent with this presumption.

Considering the matching hypothesis further, the results of Schüler et al. (2010) and Schüler and Brandtstätter (2010) deserve brief mention; these investigators found that nAch and nAff did interact with corresponding need-satisfaction to predict flow (but not SWB). In other words, higher achievers according to the PSE got more flow experience when their competence needs were met and similarly for high affiliatives and relatedness needs. We suggest that this discrepancy can be explained by the fact that flow is a measure of behavioral activity engagement, a construct which is logically linked to implicit motives, because such motives orient people toward various types of activity. The current studies focused instead on SWB, which is a global state judgment made by the person that is abstracted from particular behaviors and activities. Obviously, future research needs to explore what other variables besides flow might be influenced by interactions between motive dispositions and corresponding need-satisfactions.

Interestingly, the study findings support a basic assumption of character strengths researchers: namely, that people are better off trying to use their strengths rather than strengthen their weaknesses (Peterson \& Seligman, 2004; Peterson \& Seligman, 2006). In the current data, participants benefited from pursuing self-concordant goals that matched their dispositions (i.e., goals that played to their strengths), because they were more likely to achieve those goals and gain further satisfaction. They received less benefit from pursuing goals that did not match their dispositions (i.e., goals that did not play to their strengths). Of course, motive dispositions (what people want) and character strengths (what broad skills people have) are not the same thing, but they may be closely related constructs, given the current findings that motive dispositions are associated with satisfaction of corresponding needs. Apparently, high achievers have the skill to get what they want, as do high affiliatives, so that acting on one's motive dispositions may be akin to using one's strengths (Peterson \& Seligman, 2004). Studies 2 and 3 also suggest an intriguing vulnerability for those with strong motive dispositions; if the context does not support their dispositions, they may fail to thrive (i.e., if they get stuck with "the wrong goals" for them). In other words, those who habitually rely on a particular need for their mood-regulation and happinessboosting efforts may end up with fewer overall paths to satisfaction and may suffer disproportionately when their habit is thwarted. The world provides a variety of natural incentives, and it may be imprudent to rely too much, or in too imbalanced a way, on just one type (Sheldon \& Niemiec, 2006).
Another contribution of this research comes from the linking of the need for achievement with the thematically similar need for competence and the linking of the need for affiliation with the thematically similar need for relatedness. Although the overlap has been observed before (Schüler, et al., 2010), no prior research has made use of this similarity to try to integrate the two theories. Again, feelings of competence and feelings of relatedness may be two important incentives toward which achievers and affiliators disproportionately orient. Notably, the MDT concept of natural incentives is somewhat lacking in contemporary articulation and justification, and the SDT concept of basic needs may provide such articulation, based on evolutionary psychological reasoning. Such reasoning does not preclude the possibility that an early preponderance of one type of rewarding experience, compared with a second type, might lead to chronic dispositions to prefer the first type of reward (Emmons, 1992). However, future research will be required to test the developmental proposal that high achievers are those who experienced disproportionate amounts of competence satisfaction during childhood, and vice versa for high affiliatives and relatedness need satisfaction.

\section{Broader Implications}

These findings have important implications for the "sequential process" theory of psychological needs recently proposed by Sheldon (in press), which characterizes psychological needs as having a dual nature and two-functional role within the psychic economy. In the sequential process model, needs are said to motivate subsequent behavior when they are unmet and to reward prior behavior when they are met. Supporting this model, Sheldon, Abad, and Hinsch (2011) reported four studies showing that loneliness (relatedness need-deprivation) motivated greater Facebook use and that connectedness (relatedness need-satisfaction) rewarded greater use. The current studies also support the use of a sequential process perspective, because psychological needs were construed and measured as both chronic motives for certain types of experience (wanting, as in the MDT perspective) and positive outcomes of such motives (needing and having, as in the SDT perspective). Need-satisfaction rewards the motive dispositions, maintaining these modes of living precisely because motive-relevant behaviors provide a viable route to SWB via corresponding psychological needs.

One paradox for the needs-as-motives perspective is that Sheldon and Gunz (2009) showed that unmeet needs predicted stronger corresponding motives, whereas herein we show that stronger motives predict met needs. Although we believe this difference might be explained in a number of ways (i.e., in terms of differences between the motivation measures used, or in terms of differences between chronic and acute states of motivation, or in terms of the differences between measured satisfaction and measured dissatisfaction), future research will need to address these possibilities. The important point is that in the current data, as in the data of Sheldon et al. (2010) and Sheldon and Gunz (2009), it appears that psychological needs can be fruitfully conceptualized and measured as both motivating forces and as experiential rewards within the same study or model, potentially allowing new theoretical integration to occur.

These studies leave other questions unanswered. One important question concerns the cross-cultural generalizability of the results. 
Members of western (individualistic) societies may be more socialized to value or approach competence, whereas members of eastern (collectivistic) societies may be more socialized to value or approach relatedness (Triandis, 1995). We suggest that motive dispositions for achievement and affiliation should be associated with satisfaction of the corresponding need in any culture, even if cultures differ in their average levels of particular motive dispositions or satisfaction of particular needs. Thus, although East Asians may tend to be higher in nAff or in relatedness needsatisfaction than Americans (Sheldon et al., 2001), this should be independent of finding that those within a culture who are particularly high in one are also particularly high in the other. Still, this research remains to be done.

Despite these limitations, the current results suggest that researchers and theorists should maintain clear distinctions between what people need, what they want, and what they have. Although some people want more (or less) competence or relatedness than others, all people seem to need both. Still, wanting more may cause people to actually have (or get) more of the desired experience, providing a viable route to well-being (Sheldon \& Cooper, 2008), as long as the context is reasonably supportive of these dispositions. When the context fails, however, those with strong motive dispositions may suffer due to their potential overreliance on one type of satisfaction.

\section{References}

Atkinson, J. W. (1982). Motivational determinants of thematic apperception. In A. J. Stewart (Ed.), Motivation and society (pp. 3-40). San Francisco, CA: Jossey-Bass.

Atkinson, J. W., Heyns, R. W., \& Veroff, J. (1958). The effect of experimental arousal of the affiliation motive on thematic apperception. In J. W. Atkinson (Ed.), Motives in fantasy, action, and society: A method of assessment and study (pp. 95-104). Princeton, NJ: Van Nostrand.

Baron, R. M., \& Kenny, D. A. (1986). The moderator-mediator variable distinction in social psychological research: Conceptual, strategic, and statistical considerations. Journal of Personality and Social Psychology, 51, 1173-1182. doi:10.1037/0022-3514.51.6.1173

Baumann, N., Kaschel, R., \& Kuhl, J. (2005). Striving for unwanted goals: Stress-dependent discrepancies between explicit and implicit achievement motives reduce subjective well-being and increase psychosomatic symptoms. Journal of Personality and Social Psychology, 89, 781-799. doi:10.1037/0022-3514.89.5.781

Bentler, P. (1990). Comparative fit indices in structural models. Psychological Bulletin, 107, 238-246. doi:10.1037/0033-2909.107.2.238

Brunstein, J. C. (2008). Implicit and explicit motives. In H. Heckhausen \& J. Heckhausen (Eds.), Motivation and action (pp. 227-246). Cambridge, England: Cambridge University Press. doi:10.1017/ CBO9780511499821.010

Buss, D. M. (1991). Evolutionary personality psychology. Annual Review of Psychology, 42, 459-491. doi:10.1146/annurev.ps.42.020191.002331

Carver, C., \& Scheier, M. F. (1998). On the self-regulation of behavior. Cambridge, England: Cambridge University Press.

Deci, E. L., \& Ryan, R. M. (1985). Intrinsic motivation and selfdetermination in human behavior. New York, NY: Plenum Press.

Deci, E. L., \& Ryan, R. M. (2000). The "what" and "why" of goal pursuits: Human needs and the self-determination of behavior. Psychological Inquiry, 11, 227-268. doi:10.1207/S15327965PLI1104_01

Deci, E. L., \& Ryan, R. M. (2008). Facilitating optimal motivation and psychological well-being across life's domains. Canadian Psychology, 49, 14-23. doi:10.1037/0708-5591.49.1.14

Diener, E. (1994). Assessing subjective well-being: Progress and opportu- nities. Social Indicators Research, 31, 103-157. doi:10.1007/ BF01207052

Diener, E., Emmons, R., Larsen, R., \& Griffin, S. (1985). The Satisfaction with Life Scale. Journal of Personality Assessment, 47, 1105-1117.

Emmons, R. A. (1989). The personal strivings approach to personality. In L. A. Pervin (Ed.), Goal concepts in personality and social psychology (pp. 87-126). Hillsdale, NJ: Erlbaum.

Emmons, R. A. (1992). Motives and goals. In R. Hogan, J. Johnson, \& S. Briggs (Eds.), Handbook of personality psychology (pp. 486-512). San Diego, CA: Academic Press.

Gagné, M. (2003). The role of autonomy support and autonomy orientation in prosocial behavior engagement. Motivation and Emotion, 27, 199223. doi:10.1023/A:1025007614869

Harackiewicz, J. M., \& Sansone, C. (1991). Goals and intrinsic motivation: You can get there from here. In M. L. Maehr \& P. R. Pintrich (Eds.), Advances in motivation and achievement (Vol. 7, pp. 21-49). Greenwich, CT: JAI Press.

Hu, L., \& Bentler, P. M. (1998). Fit indices in covariance structure modeling: Sensitivity to underparameterized model misspecification. Psychological Methods, 3, 424-453. doi:10.1037/1082-989X.3.4.424

Jackson, D. (1984). Personality research form manual. Port Huron, MI: Research Psychologists Press.

Job, V., \& Brandstätter, V. (2009). Get a taste of your goals: Promoting motive goal congruence through affect-focus goal fantasy. Journal of Personality, 77, 1527-1559. doi:10.1111/j.1467-6494.2009.00591.x

Jöreskog, K. G., \& Sörbom, D. (1993). LISREL 8: Users reference guide. Chicago, IL: Scientific Software International.

Kashdan, T. B., Julian, T., Merritt, K., \& Uswatte, G. (2006). Social anxiety and posttraumatic stress in combat veterans: Relations to wellbeing and character strengths. Behaviour Research and Therapy, 44, 561-583. doi:10.1016/j.brat.2005.03.010

Kasser, T. (2002). The high price of materialism. Cambridge, MA: MIT Press.

Kehr, H. M. (2004). Implicit/explicit motive discrepancies and volitional depletion among managers. Personality and Social Psychology Bulletin, 30, 315-327. doi:10.1177/0146167203256967

Krohne, H. W., Egloff, B., Kohlmann, C.-W., \& Tausch, A. (1996). Untersuchung mit einer deutschen Form der Positive and Negative Affect Schedule (PANAS) [Investigations with a German version of the Positive and Negative Affect Schedule (PANAS)]. Diagnostica, 42, $139-156$.

Langan-Fox, J., Sankey, M. J., \& Canty, J. M. (2009). Incongruence between implicit and self-attributed achievement motives and psychological well-being: The moderating role of self-directedness, selfdisclosure and locus of control. Personality and Individual Differences, 47, 99-104. doi:10.1016/j.paid.2009.02.005

Langens, T. A., \& Schmalt, H. (2008). Motivational traits: New directions and measuring motives with the multi-motive grid (MMG). In G. J. Boyle, G. Matthews, \& D. H. Saklofske (Eds.), The SAGE handbook of personality theory and assessment. Vol. 1: Personality theories and models (pp. 523-544). Thousand Oaks, CA: Sage.

Lettner, K., Sölva, M., \& Baumann, U. (1996). Die Bedeutung positiver und negativer Aspekte sozialer Beziehungen für das Wohlbefinden. Zeitschrift für Differentielle und Diagnostische Psychologie, 17, 170186.

Lundy, A. (1988). Instructional set and Thematic Apperception Test validity. Journal of Personality Assessment, 52, 309-320. doi:10.1207/ s15327752jpa5202_12

Lyubomirsky, S., King, L., \& Diener, E. (2005). The benefits of frequent positive affect: Does happiness lead to success? Psychological Bulletin, 131, 803-855. doi:10.1037/0033-2909.131.6.803

Maslow, A. (1971). The further reaches of human nature. New York, NY: Viking Press.

McAdams, D. P. (1980). A thematic coding system for the intimacy 
motive. Journal of Research in Personality, 14, 413-432. doi:10.1016/ 0092-6566(80)90001-X

McAdams, D. P. (1996). Personality, modernity, and the storied self: A contemporary framework for studying persons. Psychological Inquiry, 7 , 295-321. doi:10.1207/s15327965pli0704_1

McClelland, D. C. (1985). Human motivation. New York, NY: Cambridge University Press.

McClelland, D. C., Koestner, R., \& Weinberger, J. (1989). How do self-attributed and implicit motives differ? Psychological Review, 96, 690-702. doi:10.1037/0033-295X.96.4.690

McClelland, D. C., \& Pilon, D. A. (1983). Sources of adult motives in patterns of parent behavior in early childhood. Journal of Personality and Social Psychology, 44, 564-574. doi:10.1037/0022-3514.44.3.564

McDonald, R. P., \& Ho, M. R. (2002). Principles and practice in reporting structural equation analyses. Psychological Methods, 7, 64082. doi: 10.1037/1082-989X.7.1.64

Murray, H. A. (1938). Explorations in personality. New York, NY: Oxford University Press.

Murray, H. A. (1943). Thematic Apperception Test. Cambridge, MA: Harvard University Press.

Niemiec, C. P., Ryan, R. M., \& Deci, E. L. (2009). The path taken: Consequences of attaining intrinsic and extrinsic aspirations in postcollege life. Journal of Research in Personality, 43, 291-306. doi: 10.1016/j.jrp.2008.09.001

Peterson, C., \& Seligman, M. (2004). Character strengths and virtues: A handbook and classification. New York, NY: Oxford University Press.

Peterson, C., \& Seligman, M. E. P. (2006). Greater strengths of character and recovery from illness. Journal of Positive Psychology, 1, 17-26. doi:10.1080/17439760500372739

Reis, H. T., Sheldon, K. M., Gable, S. L., Roscoe, R., \& Ryan, R. (2000). Daily well being: The role of autonomy, competence, and relatedness. Personality and Social Psychology Bulletin, 26, 419-435. doi:10.1177/ 0146167200266002

Richer, S. F., Blanchard, C., \& Vallerand, R. J. (2002). A motivational model of work turnover. Journal of Applied Social Psychology, 3, 2089-2113. doi:10.1111/j.1559-1816.2002.tb02065.x

Ryan, R. M. (1995). Psychological needs and the facilitation of integrative processes. Journal of Personality, 63, 397-427. doi:10.1111/j.14676494.1995.tb00501.x

Ryan, R. M., \& Deci, E. L. (2008). Self-determination theory and the role of basic psychological needs in personality and the organization of behavior. In O. P. John, R. W. Robins, \& L. A. Pervin (Eds.), Handbook of personality psychology: Theory and research (3rd ed., pp. 654-678). New York, NY: Guilford Press.

Schüler, J. (2010). Achievement incentives determine the effects of achievement-motive incongruence on flow experience. Motivation and Emotion, 34, 2-14. doi:10.1007/s11031-009-9150-4

Schüler, J., \& Brandstätter, V. (2010). How basic need satisfaction and dispositional motives interact in predicting flow experience in sport. Manuscript submitted for publication.

Schüler, J., Sheldon, K. M., \& Fröhlich, S. M. (2010). Implicit need for achievement moderates the relationship between felt competence and subsequent motivation. Journal of Research in Personality, 44, 1-12. doi:10.1016/j.jrp.2009.09.002

Schultheiss, O. C. (2008). Implicit motives. In O. P. John, R. W. Robins, \& L. A. Pervin (Eds.), Handbook of personality psychology: Theory and research (3rd ed., pp. 603-633). New York, NY: Guilford Press.

Schultheiss, O. C., \& Pang, J. C. (2007). Measuring implicit motives. In R. W. Robins, R. C. Fraley, \& R. Krueger (Eds.), Handbook of research methods in personality psychology (pp. 322-344). New York, NY: Guilford Press.

Sheldon, K. M. (2002). The self-concordance model of healthy goalstriving: When personal goals correctly represent the person. In E. L.
Deci \& R. M. Ryan (Eds.), Handbook of self-determination research (pp. 65-86). Rochester, NY: University of Rochester Press.

Sheldon, K. M. (2004). Optimal human being: An integrated multi-level perspective. Mahwah, NJ: Erlbaum.

Sheldon, K. M. (in press). Integrating behavioral-motive and experientialrequirement perspectives on psychological needs: A two process perspective. Psychological Review.

Sheldon, K. M., Abad, N., \& Hinsch, C. (2011). A two process view of Facebook use and relatedness need-satisfaction: Disconnectedness drives use and connectedness rewards it. Journal of Personality and Social Psychology, 100, 766-775. doi:10.1037/a0022407

Sheldon, K. M., \& Cooper, M. L. (2008). Goal striving within agentic and communal roles: Functionally independent pathways to enhanced wellbeing. Journal of Personality, 76, 415-447. doi:10.1111/j.14676494.2008.00491.x

Sheldon, K. M., Cummins, R., \& Khamble, S. (2010). Life-balance and well-being: Testing a two-pronged conceptual and measurement approach. Journal of Personality, 78, 1093-1134.

Sheldon, K. M., \& Elliott, A. J. (1998). Not all personal goals are personal: Comparing autonomous and controlled reasons as predictors of effort and attainment. Personality and Social Psychology Bulletin, 24, 546557. doi:10.1177/0146167298245010

Sheldon, K. M., \& Elliott, A. J. (1999). Goal striving, need-satisfaction, and longitudinal well-being: The self-concordance model. Journal of Personality and Social Psychology, 76, 482-497. doi:10.1037/00223514.76.3.482

Sheldon, K. M., Elliott, A. J., Kim, Y., \& Kasser, T. (2001). What's satisfying about satisfying events? Comparing ten candidate psychological needs. Journal of Personality and Social Psychology, 80, 325-339. doi:10.1037/0022-3514.80.2.325

Sheldon, K. M., \& Gunz, A. (2009). Psychological needs as basic motives, not just experiential requirements. Journal of Personality, 77, 14671492. doi:10.1111/j.1467-6494.2009.00589.x

Sheldon, K. M., \& Hilpert, J. (2011). The Balanced Measure of Psychological Needs (BMPN) scale: An alternative domain general measure of need satisfaction. Manuscript submitted for publication.

Sheldon, K. M., \& Houser-Marko, L. (2001). Self-concordance, goalattainment, and the pursuit of happiness: Can there be an upward spiral? Journal of Personality and Social Psychology, 80, 152-165. doi: 10.1037/0022-3514.80.1.152

Sheldon, K. M., \& Kasser, T. (1995). Coherence and congruence: Two aspects of personality integration. Journal of Personality and Social Psychology, 68, 531-543. doi:10.1037/0022-3514.68.3.531

Sheldon, K. M., \& Krieger, L. K. (2007). Understanding the negative effects of legal education on law students: A longitudinal test and extension of self-determination theory. Personality and Social Psychology Bulletin, 33, 883-897. doi:10.1177/0146167207301014

Sheldon, K. M., \& Niemiec, C. (2006). It's not just the amount that counts: Balanced need-satisfaction also affects well-being. Journal of Personality and Social Psychology, 91, 331-341. doi:10.1037/00223514.91.2.331

Sheldon, K. M., Ryan, R., Deci, E., \& Kasser, T. (2004). The independent effects of goal contents and motives on well-being: It's both what you pursue and why you pursue it. Personality and Social Psychology Bulletin, 30, 475-486. doi:10.1177/0146167203261883

Sobel, M. E. (1982). Asymptotic intervals for indirect effects in structural equations models. In S. Leinhart (Ed.), Sociological methodology 1982 (pp. 290-312). San Francisco, CA: Jossey-Bass.

Sokolowski, K., Schmalt, H., Langens, T. A., \& Puca, R. M. (2000). Assessing achievement, affiliation, and power motives all at once: The multi-motive grid (MMG). Journal of Personality Assessment, 74, 126145. doi:10.1207/S15327752JPA740109

Stumpf, H., Angleitner, A., Wieck, T., Jackson, D. N., \& Beloch-Till, H. 
(1985). Deutsche Personality Research Form (PRF) [German Personality Research Form (PRF)]. Göttingen, Germany: Hogrefe.

Tanaka, J. (1987). How big is big enough? Sample size and goodness-of-fit indices in structural equation models with latent variables. Child Development, 58, 134-146. doi:10.2307/1130296

Thrash, T. M., Elliot, A. J., \& Schultheiss, O. C. (2007). Methodological and dispositional predictors of congruence between implicit and explicit need for achievement. Personality and Social Psychology Bulletin, 33, 961-974. doi:10.1177/0146167207301018

Tooby, J., \& Cosmides, L. (1990). On the universality of human nature and the uniqueness of the individual: The role of genetics and adaptation. Journal of Personality, 58, 17-67. doi:10.1111/j.14676494.1990.tb00907.x

Triandis, H. (1995). Individualism and collectivism. Boulder, CO: Westview Press.

Vansteenkiste, M., Timmermans, T., Lens, W., Soenens, B., \& Van den Broeck, A. (2008). Does extrinsic goal framing enhance extrinsic goaloriented individuals' learning and performance? An experimental test of the match perspective versus self-determination theory. Journal of Educational Psychology, 100, 387-397. doi:10.1037/0022-0663.100.2.387 Watson, D., Clark, L. A., \& Tellegen, A. (1988). Development and vali- dation of brief measures of positive and negative affect: The PANAS scale. Journal of Personality and Social Psychology, 54, 1063-1070. doi:10.1037/0022-3514.54.6.1063

Weinberger, J., \& McClelland, D. C. (1990). Cognitive versus traditional motivational models? Irreconcilable or complementary? In E. T. Higgins \& R. M. Sorrentino (Ed.s), Handbook of motivation and cognition (Vol. 2, pp. 562-597). New York, NY: Guilford Press.

White, R. (1959). Motivation reconsidered: The concept of competence. Psychological Review, 66, 297-333. doi:10.1037/h0040934

Winter, D. G. (1994). Manual for scoring motive imagery in running text. Unpublished instrument, University of Michigan, Ann Arbor.

Winter, D. G. (1999). Linking personality and "scientific" psychology: The development of empirically derived Thematic Apperception Test measures. In L. Gieser \& M. I. Stein (Eds.), Evocative images: The Thematic Apperception Test and the art of projection (pp. 107-124). Washington, DC: American Psychological Association. doi:10.1037/10334-008 